\title{
Preparation Method of High Resilience Nonslip Basketball Sole Composite Material
}

\author{
Zheng Wang, ${ }^{1}$ Yihe Liu, ${ }^{2}$ and Shuang Zhang $\mathbb{D}^{2}$ \\ ${ }^{1}$ College of Sport, Neijiang Normal University, Neijiang, 641100 Sichuan, China \\ ${ }^{2}$ School of Artificial Intelligence, Neijiang Normal University, Neijiang, 641100 Sichuan, China \\ Correspondence should be addressed to Shuang Zhang; zhang.s@njtc.edu.cn
}

Received 5 January 2022; Revised 9 February 2022; Accepted 21 February 2022; Published 4 March 2022

Academic Editor: Awais Ahmed

Copyright (C) 2022 Zheng Wang et al. This is an open access article distributed under the Creative Commons Attribution License, which permits unrestricted use, distribution, and reproduction in any medium, provided the original work is properly cited.

\begin{abstract}
Today, with the gradual improvement of material living standards, basketball is becoming more and more popular, and the pursuit of sports protection and shoes performance is also getting higher and higher. A good pair of basketball shoe soles can help athletes solve these problems. This article is aimed at studying the preparation of basketball shoe soles made of high resilience and nonslip composite materials. Under this research topic, this paper proposes a method for the design of shoe sole antislip pattern and the measurement method of composite material's resilience performance and a 3D printing method based on FDM technology to print the shoe sole. At the same time, an experiment was designed to explore the high resilience and antislip performance of the sole. And the stability of printing technology is analyzed to ensure the quality of sneaker printing. The experimental results in this article show that the antislip performance of the sole printed by the above method design has been improved by $31 \%$, and the rebound capacity has been improved by $44 \%$. At the same time, the rebound time is significantly shorter than that of several common basketball shoes on the market.
\end{abstract}

\section{Introduction}

The correct selection of sports shoes with appropriate functions is an important link that sports enthusiasts should not ignore. The structural design and material function of sports shoes play a very important role in protecting the human body and improving sports performance. The basketball population in China is increasing day by day, and there is a great demand for basketball shoes. Various manufacturers compete with each other for the research and development of basketball shoes. The functionality and professionalism of basketball shoes are the main considerations for fans. In a fierce basketball game, if a person's foot touches the ground, it will receive an impact from the ground to the human body. The impact of the impact can cause various damages to all parts of the human body. For example, if you twist your feet hard, your ankle will be sprained, your feet will be swollen, and pain will occur. At the same time, in basketball, excessive footsteps will move laterally, putting a burden on muscles and bones, and eventually, joint skills will decline, and tendons may become stiff. Basketball players will exercise their knees after a lot of sports. Injuries, ankle and middle finger injuries, are very common. At the same time, the antiskid of basketball shoes is also extremely important, which can effectively prevent athletes from slipping and causing ankle injuries.

However, there are two problems with the slip resistance and high elasticity of current basketball shoes. First of all, companies have exaggerated the antislip and elastic functions of basketball shoes, causing people to misunderstand the understanding and consumption of basketball shoes; second, as the basic performance of basketball shoes, the antislip and rebound ability has not received full attention from basketball shoe manufacturers. Most basketball shoes are designed with nonslip mode, and the structure is more beautiful than the actual function. The problem of ankle sprain caused by basketball foot slip cannot be solved at all. With this in mind, we believe that the study of the sole pattern and resilience of basketball shoe soles has important value and importance.

The sole design of basketball shoes is the focal point of the entire sports shoe. Basketball shoes are a prerequisite 
for excellent performance. Basketball shoes provide excellent protection and elasticity, and most of these basketball shoes have excellent bottom design. With the increasing influence of basketball, more and more people have begun to devote themselves to the design of high resilience and nonslip performance of the soles of basketball shoes. Liang et al. proposed a feasible method to select the material of the beam collector in the HPM device. First, he compared the elasticity of several metals to strong relativistic electron beam (IREB) bombardment. This resilience is mainly determined by the density and melting point of the material. Compared with stainless steel, copper, molybdenum, and tungsten, titanium shows good resilience. Therefore, the theoretical results indicate that titanium is a promising material that can be used in HPM equipment [1]. However, this research is only an analysis based on theoretical research, and no experiment is used to verify the conclusion. Kakunuri et al. use the controlled pyrolysis of electrospun SU-8 photoresist nanofibers to fabricate a binder-free carbon nanofiber mesh on a stainless steel wafer collector. The electrochemical performance of the prepared carbon nanofiber mesh was studied by conducting charge and discharge experiments under different current densities. This excellent electrochemical performance can be attributed to the smaller lithium-ion diffusion length and the elasticity in the entangled carbon nanofibers to adapt to the volume changes during charging and discharging [2]. However, under different current densities, the charging and discharging experiments did not compare the performance under low current and high current, and there are still some deficiencies. Han et al. proposed that in order to make the structural noise of ship-borne equipment reach the prescribed standards, the excitation force of the equipment should be limited, and antivibration devices such as elastic supports and bellows should be added. Since structural noise depends on the design of the equipment base, it is important to achieve a low-vibration base design. In his research, the typical pump base was optimized using design of experiment (DOE) and computer-aided engineering (CAE) techniques to minimize the vibration transmitted from the equipment base to the ground [3]. However, there is still no clear statement on how to achieve a certain degree of antivibration through the structure of the material. Ju et al. conducted a parametric study on field data of more than 100 locations measured under two heavy object impact sources. The results show that the size of the room and the dynamic stiffness of the elastic floor mat material are the main factors affecting the impact noise of the floor. According to the analysis results, a simple regression equation of the impact noise of the heavy hammer is proposed. These formulas are expected to guide engineers to consider floor impact noise levels in the early design stage before construction [4]. Among them, the elasticity of the elastic floor mat material can be well used in our design. Xiao et al. tested the $4 \%$ cement stabilized base mixture in different system laboratories, including unconfined compressive strength and splitting strength of curing time, $90 \mathrm{~d}$ compression and splitting elastic modulus, erosion resistance, freeze-thaw resistance, dry shrinkage, and temperature shrinkage. And he conducted a comparative analysis of the test results [5].
We can use its experimental experience on elastic modulus for reference in our material elasticity experiment. Kim et al. believe that recycled synthetic resin materials produced from waste vinyl and waste plastics contain many foreign substances. Such plastic products made of recycled resin materials containing foreign matter are of poor quality, and their strength and rigidity are reduced. Foreign objects include heavy metals, cement, foil, dyed paper, and dust. After installing the manufactured equipment, recycled resin is produced, and its heavy metal content is evaluated. Recycled synthetic resin materials are also used in plastic products, and their strength is evaluated. In addition, changes in production are also evaluated [6]. For the preparation of PVC synthetic resin, we can use it in the preparation of shoe soles. Sun et al. modified the surface of iron-rich sludge with silane coupling agent KH550 to prepare modified iron-rich sludge, which was then filled into polyvinyl chloride to prepare $\mathrm{PVC} / \mathrm{KH} 550-\mathrm{FeS}$ composite materials [7]. By modifying FeS, its heat resistance, stretchability, and other related properties can be improved very well, and the same can be done in the preparation of sneaker sole material PVC. By blending or adding various additives (such as antioxidants, etc.) to improve to enhance functional performance, Shen et al. classify polymer-based building materials into three categories: substrates, coatings, and adhesives according to their uses. And he carefully demonstrated the latest progress in their preparation and application [8]. Most of the appeal literature is about the consideration of elasticity, and the experimental analysis of the specific parameters of elasticity has not been explored in detail. The experimental part is also researched on the basis of theory, and the external environment factors in the actual use process are not taken into consideration. The innovation of this article lies in the theoretical support of the pattern design and antiskid design of basketball shoes. This article designs its antiskid pattern and resilience ability and designs experiments to analyze and compare its antiskid ability and resilience ability. At the same time, 3D printing technology is used as technical support to print the soles of sneakers in batches. The quality problems of sneakers that may be caused by parameter problems in the $3 \mathrm{D}$ printing process are also analyzed, and the influence of irrelevant factors is excluded, which can ensure the performance of sneakers while ensuring the output.

\section{Sole Performance Design Method}

2.1. Shoe Sole Antislip Pattern Design. The characteristics of the outer layer of the venue, such as material, reinforced hardness, and microhardness, will greatly affect the performance of antislip and wear resistance. In the link where the field and the pattern maintain continuous friction, due to the action of force and heat, the outer layer of contact has obvious changes (the antiskid pattern of the sole is worn, the sole is deformed, etc.), and such changes also affect the performance of friction loss. The outer morphology and microscopic contact of the field and the pattern continue to change during the friction process [9]. In addition, the microscopic components of the friction outer layer will also 
appear to be cracked and transferred and then act on the shape of the contact outer layer, so that the antislip and abrasion performance of the outsole pattern will be significantly changed. Therefore, the status of the venue will be directly related to the functional attributes of the outsole pattern (floor humidity, antiskid ability, and floor material of the arena, etc.). When there are differences in venues, different outsole patterns should be designed (square, dotted, and divergent). The study of different sole patterns plays a vital role in the antislip performance of the soles. A good and suitable sole pattern can greatly improve the antislip properties of the soles [10].

The shoe soles with square pattern and small dot pattern have the best slip resistance on asphalt pavement and the second place on cement pavement. This is because both cement roads and asphalt roads are rough surfaces, and the soles are in surface contact when they are in contact with them. The contact area between the small dot pattern soles and the cement roads and asphalt roads is obviously smaller than that of the square pattern soles. Therefore, the test results of cement pavement and asphalt pavement are consistent. In other words, the sliding resistance of the sole of the square pattern is greater than the sliding resistance of the sole of the small dot pattern. The type of friction surface is an external factor and cannot be controlled. DuShaxun [11] of Shaanxi University of Science and Technology and others used two continuous, four continuous, and sliding block samples to study the antiskid properties of wood, cement, and marble on three different pavements. The double-sided continuous mode is composed of one or more decorative elements, and a specific curve is used as the skeleton to form a unit mode, which is arranged continuously according to a specific space, distance, and direction to form a regular pattern. The square continuous pattern is a pattern that uses one or more decorative elements to form a basic unit. It is repeatedly configured in a specific space according to a specific bone structure, and it can be expanded and continued indefinitely (it stretches through infinite stacking and cascading). In the experiment, the marble surface is the smoothest, the pattern that touches the ground is the largest, the adsorption between molecules is the strongest, so the friction between the ground and the sole of the shoe is the largest, and the sliding performance is the highest. However, due to the different places where various types of shoes are used (concrete road, indoor court, outdoor plastic court, etc.), that is, the road conditions are different, the pattern design is not single (zoomair, get, regular pattern, and chevron), it needs to be designed according to the external environment and different uses of the sole. The analysis of the foundation state of the basketball court mainly focuses on its surface shape. The characteristics of the foundation shape have a great influence on the movement function of the sole and the pattern design of the sole. The contact surface between the pattern of the shoe sole and the ground is composed of tiny raised peaks and valleys of various shapes. The shape of the thick peak of the contact surface between the outer Tor and the field is usually an ellipsoid. Since the contact size of the ellipsoid is much smaller than its own radius of curvature, it can almost be regarded as a sphere. The con- tact of two planes can be regarded as the contact of uneven spheres, which simulates the contact of rough surfaces in the ideal state [12].

2.1.1. Basketball Shoes. In the main distribution map of plantar pressure under different walking postures, the main force area and sliding trend of the stressed foot pressure are analyzed by measuring the plantar pressure of different adults' bare feet under different walking postures (duck gait, scissor gait, rooster gait, jumping gait, etc.). This coincides with the design of the circular pattern on the inner side of the forefoot of the basketball shoe. According to Figure 1 (measured gait is scissor gait), the analysis of the sliding trend of the stressed foot under different walking postures can also be used to design soles with different pattern directions for shoes of different purposes [13].

The circular outsole pattern is mostly used in basketball shoes (as shown in Figure 2). The outer sole pattern is usually the center of the circle on the inner side of the front sole. Because when a basketball player turns around while holding the ball, with one foot as the axis, the center of gravity of the body will fall on the inner side of the forefoot (resulting in larger hands on the forefoot of the sole, increased wear and tear, and easy to cause pattern wear). Designing a pattern with a heart shape here can make it easier for basketball players to do this technical action, turning more sensitive and saving effort. This pattern is especially suitable for big players.

\subsection{Determination of Elastic Properties of Shoe Sole Composite Materials}

2.2.1. Determination of Poisson's Ratio. Poisson's ratio is used to express the elastic properties of materials. (Poisson's ratio refers to the ratio of the absolute value of the transverse normal strain to the axial normal strain when the material is in unidirectional tension or compression, also known as the transverse deformation coefficient, which is an elastic constant that reflects the transverse deformation of the material). Poisson's ratio is defined as the absolute value of the ratio of the transverse strain A caused by the uniformly distributed longitudinal stress to the corresponding longitudinal strain $\mathrm{B}$ within the proportional limit of the material, namely,

$$
\mu=\frac{-\varepsilon_{x}}{\varepsilon_{y}} .
$$

At the same time, Poisson's ratio can be described by material performance parameters such as elastic modulus $\mathrm{E}$, bulk modulus K, and shear modulus G [14]. For linear materials, the following relationships exist:

$$
\begin{aligned}
\mu & =\frac{1}{2} \frac{(3 K-2 G)}{(3 K+2 G)}, \\
\mu & =\frac{E}{2 G-1}, \\
\mu & =\frac{1-E / 3 K}{2} .
\end{aligned}
$$



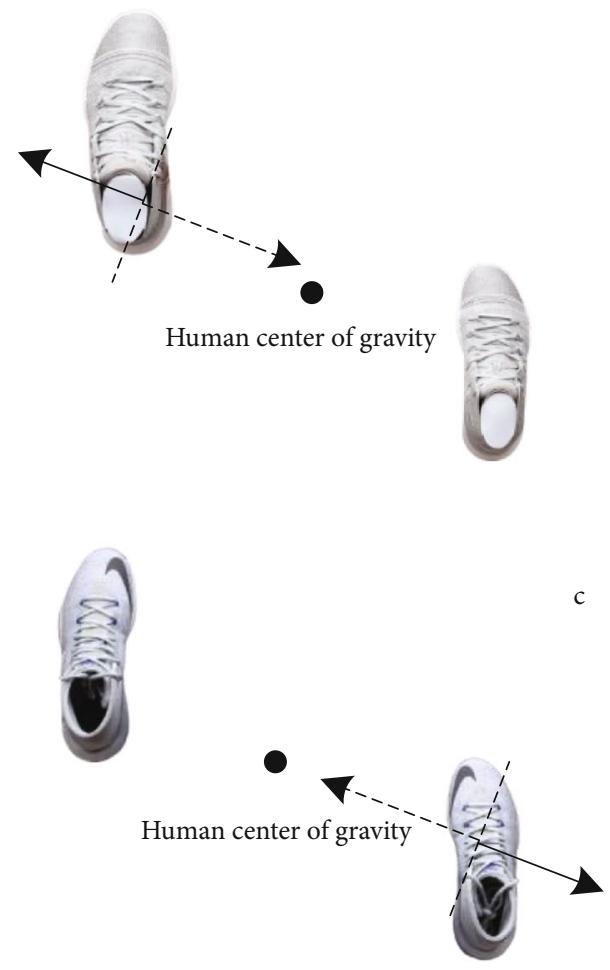

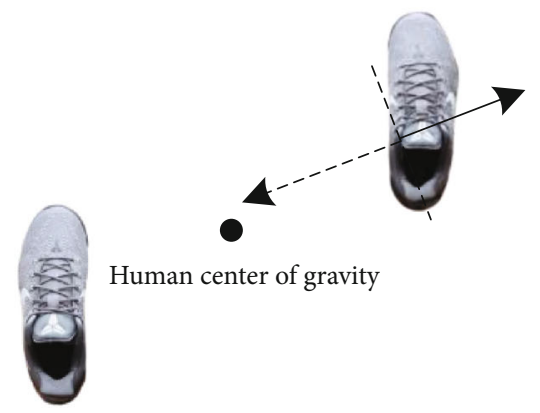

d

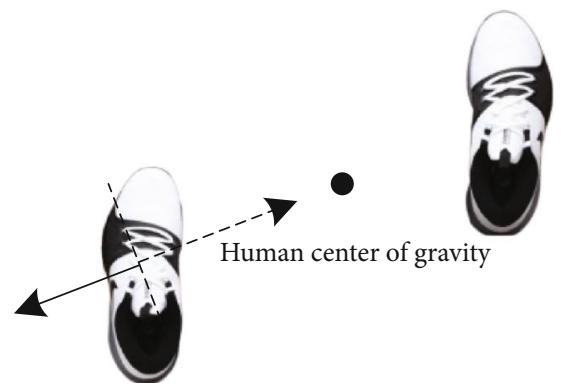

Figure 1: Analysis of the sliding trend of the stressed foot in different walking postures.
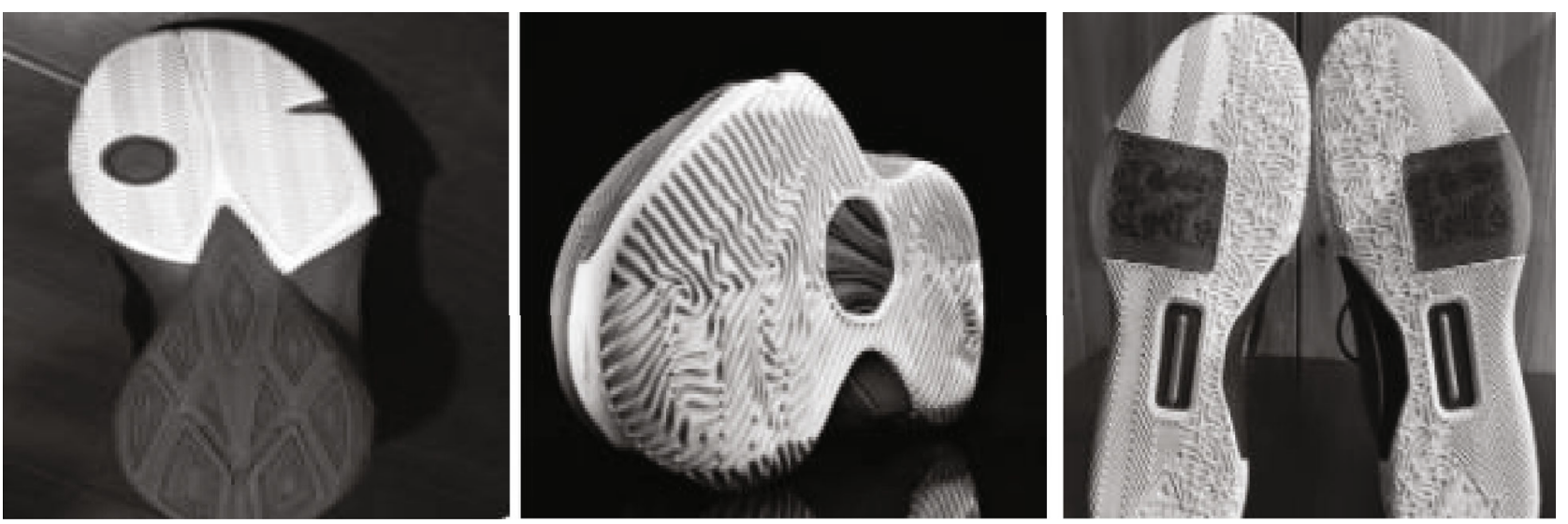

FIGURE 2: Basketball shoes with nonslip patterns.

When two of the three quantities of the material's elastic modulus $\mathrm{E}$, shear modulus $\mathrm{G}$, and bulk modulus $\mathrm{K}$ are known, the Poisson's ratio can be calculated.

For the Poisson's ratio of isotropic linear elastic materials, expression (1) is fully applicable. In the case of viscoelastic materials, Poisson's ratio is a parameter related to both temperature and load time. According to the nature of the load, it can be divided into static viscoelastic Poisson's ratio and dynamic viscoelastic Poisson's ratio $[15,16]$. The former represents the transverse strain response to longitudinal strain under static load conditions, and the latter represents the transverse strain response to longitudinal strain.
Under dynamic load conditions, it represents the response to longitudinal strain. According to the viscoelastic properties of the material, the distortion has hysteresis. Therefore, we have sufficient reasons to believe that the Poisson's ratio of viscoelastic materials is more complicated.

Starting from the definition of Poisson's ratio, this article uses a static strain gauge to determine the Poisson's ratio of the resin matrix according to the full-bridge connection method, as shown in Figure 3. R1, R2, R3, and R4 are resistance strain gauges, R1 and R3 measure longitudinal strain, $\mathrm{R} 2$ and R4 measure lateral strain, and RL is a temperature compensation sheet. The full bridge approach we use can 
efficiently utilize the concept of double differential. Therefore, the output voltage can reach as much as 4 times of the single-arm output voltage, which can greatly improve our measurement sensitivity in the actual measurement [17].

The measurement of Poisson's ratio is carried out under relaxed conditions, that is, the strain of pure resin material is compressed by $2 \%$, and the change process of Poisson's ratio with time in 100 minutes is measured. Among them, the proportion of the test piece is $1: 1$ according to the volume ratio of resin to curing agent, and the plasticizer is 5\% volume fraction of dibutyl phthalate and xylene agent, pouring the test piece in a $50 \mathrm{ml}$ syringe and cutting it according to a certain size. The measurement result is shown as the solid line in Figure 4.

It can be found from Figure 4 that the Poisson's ratio of pure resin material also has relaxation characteristics, gradually decreasing until it stabilizes. The Poisson's ratio under relaxation conditions of viscoelastic materials is similar to the relaxation modulus, and the expression of attenuation series can also be used to approach the experimental data [18-20]. Using the origin curve fitting function, the result of Poisson's ratio can be fitted to the dashed line in the figure above, and the fitting curve expression is:

$$
\mu(x)=0.419+0.059 e^{-1008 x}-0.054 e^{-0.031 x}+0.062 e^{-0.022 x} .
$$

2.2.2. Calculation of the Relaxation Modulus of the Combined Unit. For a completely elastic material, there is such a relationship between the shear modulus and the elastic modulus and Poisson's ratio:

$$
G=\frac{E}{2(1+\mu)}
$$

But for linear viscoelastic materials, the relationship between shear modulus and elastic modulus and Poisson's ratio is related to time, and there is such an implicit relationship:

$$
\int_{0}^{t} G(x-\tau) \frac{\partial \mu(\tau)}{\partial x}=\frac{E(x)}{2-G(x)}[1+\mu(0)] .
$$

Differentiate both sides of formula (5) to get:

$$
G(0) \frac{\partial \mu(x)}{\partial x}=\frac{\partial E(x)}{\partial x}-\frac{\partial G(x)}{\partial x}[1+\mu(0)]
$$

where:

$$
G(0)=\frac{E(0)}{2(1+\mu(0))} .
$$

$E(0)$ and $\mu(0)$ are directly determined from the experiment:
Solutions have to:

$$
\frac{\partial G(x)}{\partial x}=\frac{((\partial E(x) / \partial x)-G(0)(\partial \mu(0) / \partial x))}{[1+\mu(0)]} .
$$

2.3. 3D Printing Process Based on FDM Technology. According to the different printing methods of each layer in the molding process, the mainstream methods of $3 \mathrm{D}$ printing currently include fused deposition modeling (FDM), SLS, LOM, and SLA. However, the layered printing methods and materials used in the above technologies are quite different, and they all have their own advantages and disadvantages, and the fields of use are also different. In this paper, here's the advantage: additive manufacturing industry advances FDM 3D printers are feature-rich and can manufacture durable parts from your computer-aided design documents (CAD files). The parts are so robust that they can be used as high-level concept models, functional prototypes, manufacturing tools, and production parts. Engineers can produce a variety of products simply by loading different files and materials, which no other traditional machining process can do. FDM technology is used to $3 \mathrm{D}$ print the soles of sneakers to prepare the high-resilient nonslip sneakers we need [21].

2.3.1. Fused Deposition Modeling (FDM). In fused deposition modeling (FDM), the thermoplastic material is melted by a heated nozzle, and the molten material is extruded from the nozzle by extrusion and friction, and it is coated on the worktable according to the slice model, and the parts are layer by layer [22].

The principle of FDM is shown in Figure 5, which shows a dual-nozzle printer. The filamentous prototype material (typically $1.75 \mathrm{~mm}$ or $3 \mathrm{~mm}$ in diameter) and the support material are printed by different nozzles. Usually, the support material will be made of characteristic materials (such as water-soluble materials), so that it can be removed by the corresponding method after printing. The coiled wirelike prototype material and supporting material pass through the wire feeding structure, and the wire is sent to the nozzle to be heated to a molten state. Then, according to the distribution data of the slice model on this layer, the corresponding prototype or supporting material is squeezed at the corresponding position, and it is coated on the workbench to gradually complete an entire layer. When a layer is completed, the nozzle rises a layer height distance. Then, the next layer is melted, and the newly coated layer is bonded to the previous layer, and so on, until the entire preliminary solid shape is completed. After the overall modeling is completed, the supporting materials are removed, the rough burrs on the solid surface are trimmed and then painted, polished, and colored as needed. Single-jet printing means that the prototype and supporting materials use the same material and the same nozzle [23].

The principle of fused deposition molding is easy to understand, simple in structure, and convenient to operate. PLA (polylactic acid) and various ABS plastics are often used. The materials are mostly in rolls and filaments, which are easy to carry and replace. At the same time, the overall 


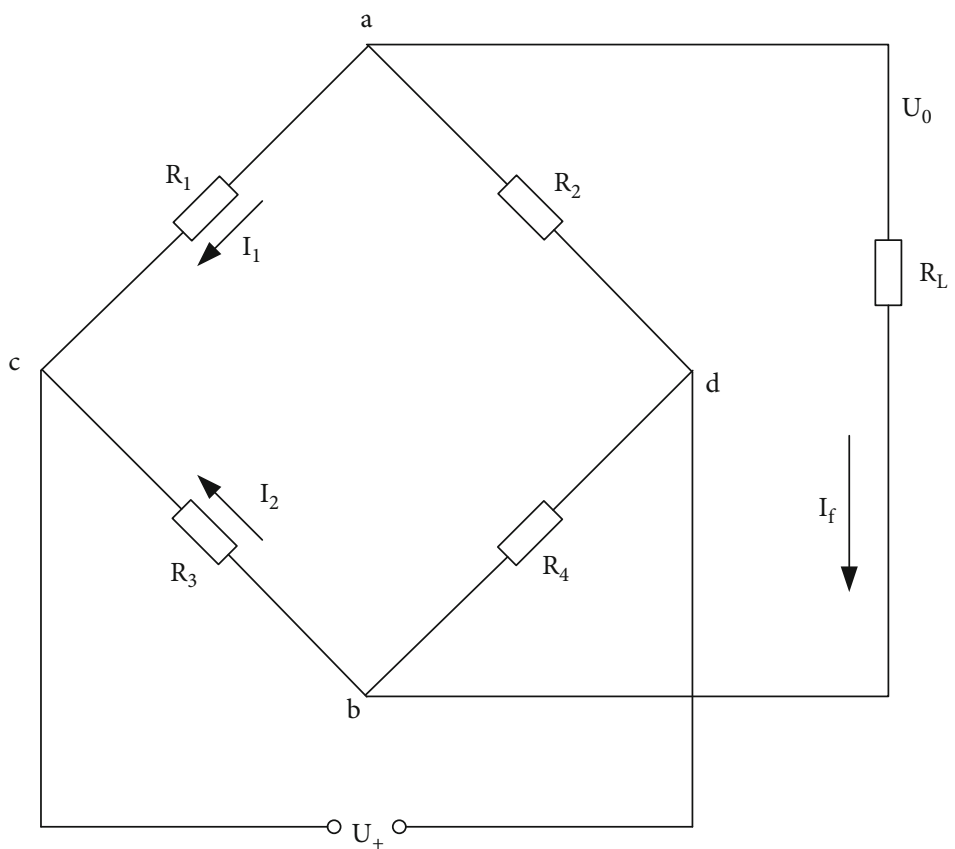

FIGURE 3: Full bridge circuit connection.

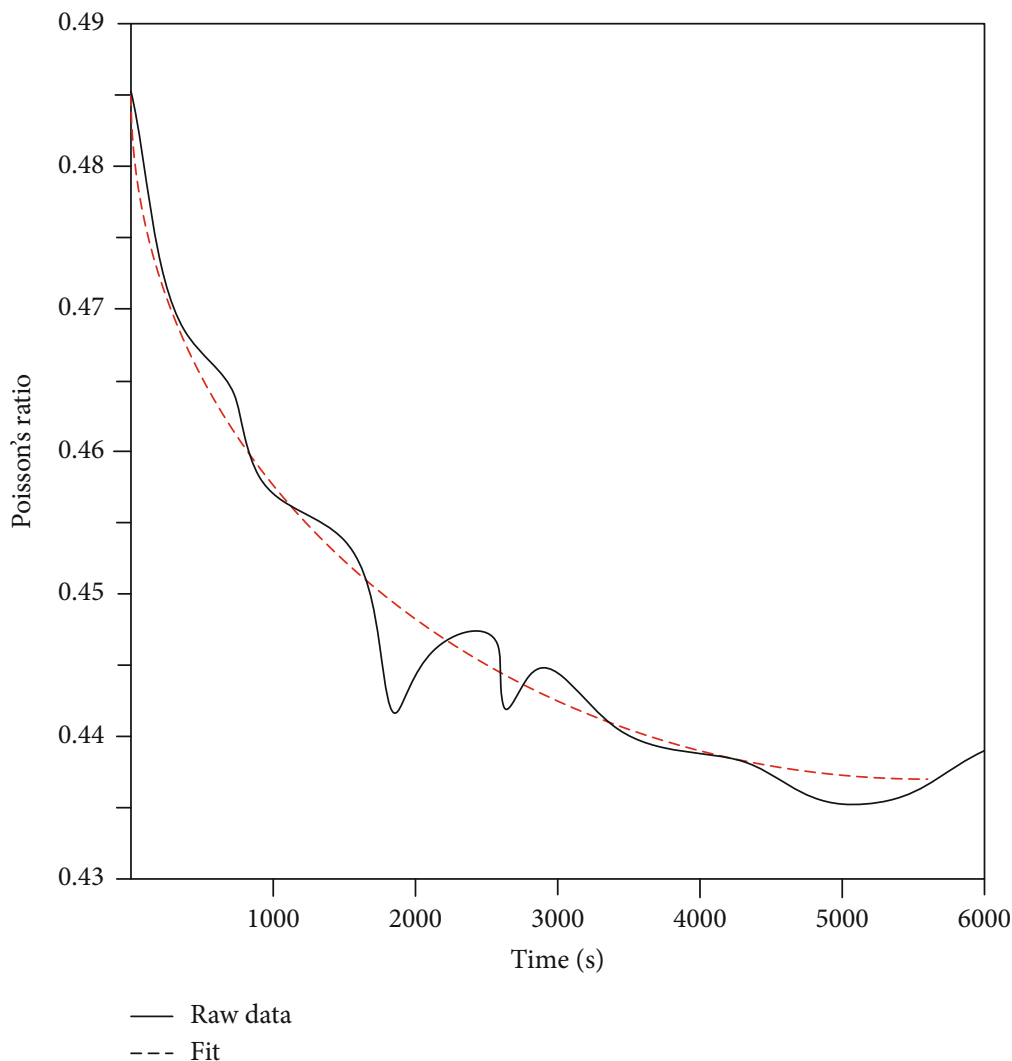

FIGURE 4: Poisson's ratio measurement results.

price of equipment and materials is relatively cheap (FDM, SLA, 3DP, SLS, LOM, and PCM). It is the most commonly used and popular 3D printing method in the current market. It has impressive performance in desktop and industrial printing. The disadvantage is that supporting materials are required, and the printing speed of the mechanical nozzle is slow, and the accuracy is slightly insufficient when making high-precision parts. 


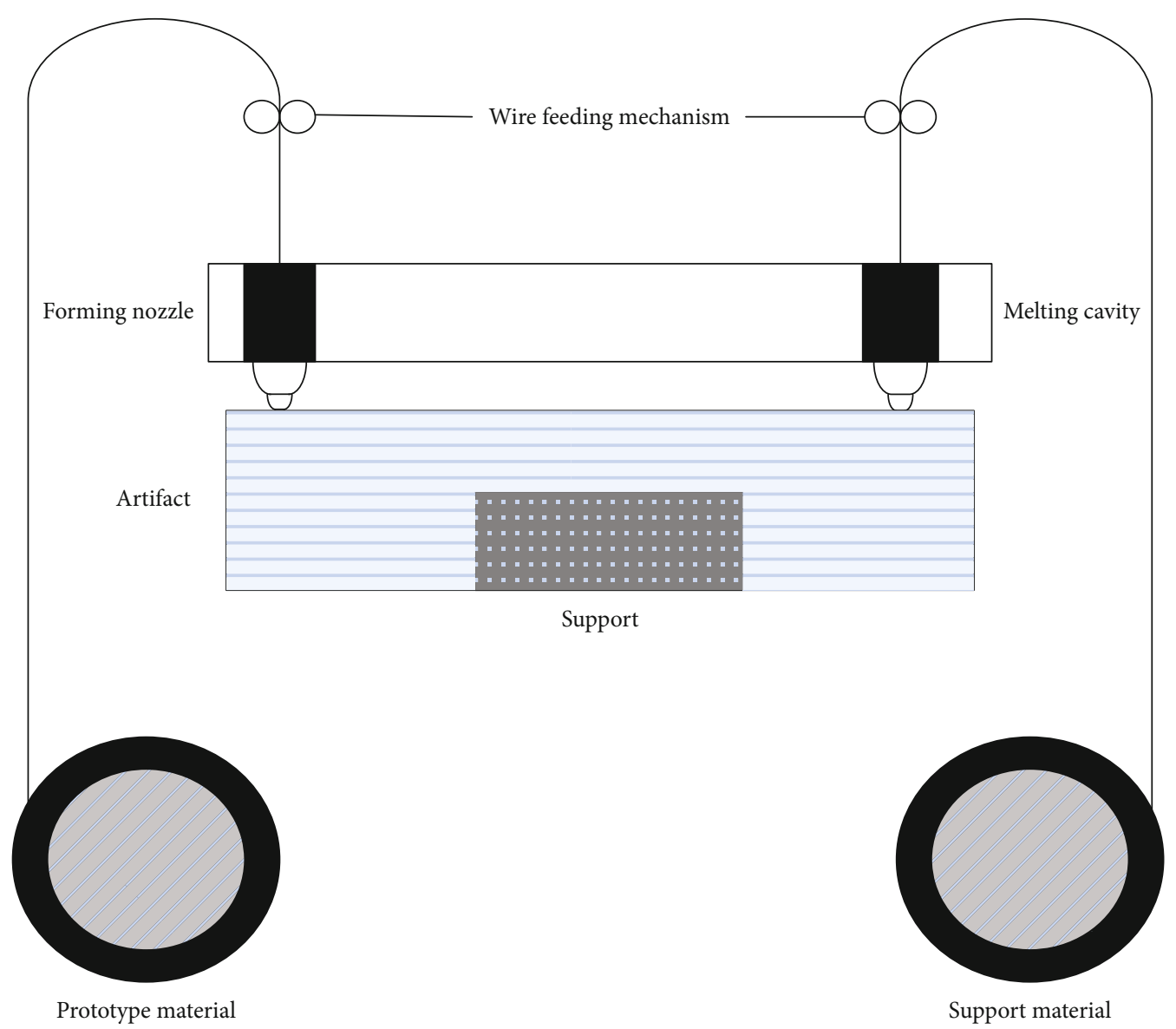

Figure 5: Fused deposition molding method.

\section{Experiment}

3.1. The Antiskid Performance of the Sole of Basketball Shoes. According to the test data information given by "Underwriters Laboratories (UL)" and other institutions, when the friction coefficient does not exceed 0.4 , it corresponds to a very dangerous interval, that is, it is extremely easy to slip. The friction coefficient is in the range of 0.5 to 0.6 , which is the basic safety range. The friction coefficient $p>0.6$, which is in a very safe range. This experiment is to use this standard as the antiskid performance standard of sneakers to conduct experimental investigations. The objects of investigation are 6 common antiskid basketball shoes on the market and experimental shoes printed by FDM technology combined with 3D printing technology (30 pairs of shoes of each brand were sampled for experimental investigation). The relevant parameters of the experimental objects are shown in Table 1.

As shown in Table 2, there are seven groups of test subjects. Let them move on the relatively dry-pressed ceramic floor, keeping the moving direction to slide forward horizontally. The antiskid friction coefficient of ordinary sports shoes is $0.73 \sim 1.25$ (the average value is 0.98 ). Sliding the heel forward on the dry-pressed ceramic floor tiles, the antiskid friction coefficient of ordinary sports shoes is 0.67 0.98 (average value is 0.80 ). It can be seen that under dry conditions, the friction coefficients of ordinary sports shoes sliding forward horizontally and the heel sliding forward are both greater than 0.6. It is in a very safe range, and the sole has excellent antislip properties.

As shown in Table 3, we moved seven groups of test subjects on the pressed ceramic floor filled with distilled water, keeping the direction of movement as horizontal and sliding forward. The antiskid friction coefficient of ordinary sports shoes is $0.59 \sim 0.75$ (average value is 0.65 ), which is between the basic safe range and the very safe range. Sliding forward on the heel of pressed ceramic floor tiles with distilled water, the anti-skid friction coefficient of ordinary sports shoes is $0.37 \sim 0.58$ (average value is 0.47 ). The average value of friction coefficient is in the range of 0.5 to 0.6 , which is in the basic safe range. Only sample no. 2 has a sole friction coefficient of 0.37 , which is in a very dangerous range.

From this, we can get the size of the forward horizontal sliding friction coefficient, which depends on the friction between the entire sole and the tile surface. The contact friction part between the heel and the tile surface is also another key factor that affects the friction coefficient of the forward horizontal sliding.

\subsection{Resilience Performance Test of Composite Materials for Preparing Shoe Soles}

3.2.1. Experimental Method. The tensile performance test of the composite material for preparing shoe soles is carried out in accordance with GB/T14337-2008. 
TABLE 1: Related parameters of experimental sneakers.

\begin{tabular}{lccc}
\hline Group & Brand & Price & Antislip parameters \\
\hline 1 & Nike & 1299 & 0.71 \\
2 & Adidas & 2499 & 0.74 \\
3 & Anta & 599 & 0.68 \\
4 & Li Ning & 899 & 0.64 \\
5 & Jordan & 800 & 0.66 \\
6 & Peak & 500 & 0.65 \\
7 & FDM & - & - \\
\hline
\end{tabular}

TABLE 2: Sliding condition of shoe soles on dry-pressed ceramic floor tiles.

\begin{tabular}{lcc}
\hline Sliding direction & Slide forward & Swipe back \\
\hline 1 & 1.1 & 0.98 \\
2 & 0.8 & 0.7 \\
3 & 0.73 & 0.67 \\
4 & 0.8 & 0.72 \\
5 & 0.86 & 0.76 \\
6 & 1.13 & 0.89 \\
7 & 1.05 & 0.85 \\
\hline
\end{tabular}

TABLE 3: Sliding condition of shoe soles on pressed ceramic floor tiles with distilled water.

\begin{tabular}{lcc}
\hline Sliding direction & Slide forward & Swipe back \\
\hline 1 & 0.66 & 0.4 \\
2 & 0.61 & 0.37 \\
3 & 0.59 & 0.58 \\
4 & 0.6 & 0.41 \\
5 & 0.61 & 0.54 \\
6 & 0.7 & 0.53 \\
7 & 0.71 & 0.5 \\
\hline
\end{tabular}

TABLE 4: Elastic performance test results of different brands of sole composite materials.

\begin{tabular}{lcc}
\hline Group & Breaking strength & Elastic modulus \\
\hline 1 & 5.34 & 1002 \\
2 & 5.11 & 854 \\
3 & 4.79 & 762 \\
4 & 4.36 & 694 \\
5 & 4.23 & 652 \\
6 & 4.02 & 669 \\
7 & 5.97 & 1283 \\
\hline
\end{tabular}

First, equilibrating the prepared shoe sole composite material sample in a test environment with a temperature of $20 \pm 3^{\circ} \mathrm{C}$ and a humidity of $65 \pm 5 \%$ for 24 hours.
TABLE 5: Test results of resilience performance of different brands of sole composite materials.

\begin{tabular}{lccc}
\hline Group & $\begin{array}{c}\text { Height before } \\
\text { pressing }\end{array}$ & $\begin{array}{c}\text { Height after } \\
\text { pressing }\end{array}$ & $\begin{array}{c}\text { Rebound } \\
\text { time }\end{array}$ \\
\hline 1 & 2.3 & 2.28 & $8.6 \mathrm{~s}$ \\
2 & 2.5 & 2.47 & $7.8 \mathrm{~s}$ \\
3 & 2.8 & 2.75 & $9.1 \mathrm{~s}$ \\
4 & 2.3 & 2.29 & $8.8 \mathrm{~s}$ \\
5 & 2.5 & 2.5 & $7.9 \mathrm{~s}$ \\
6 & 2.2 & 2.19 & $8.2 \mathrm{~s}$ \\
7 & 2.4 & 2.39 & $7.1 \mathrm{~s}$ \\
\hline
\end{tabular}

Adjusting the electronic multifunction strength machine to the normal state, setting the pretension to $0.5 \mathrm{cN}$, the pullup force value of $1 \mathrm{cN}$, the clamping distance of $20 \mathrm{~mm}$, and the stretching speed of $10 \mathrm{~mm} / \mathrm{min}$. Tensile tests were carried out on the composite materials of the soles of seven groups of different brands from 1 to 7 , respectively, and the number of experiments was 50 times in total.

3.2.2. Experimental Results. Table 4 shows the average experimental results of the composite materials of seven groups of different brands of shoe soles.

From the data in Table 4, we can see that the elastic parameters of several common brands on the market have reached a relatively excellent range, and the elastic modulus of the sole prepared in this experiment is 1283 , and the breaking strength is 5.97. In that respect, they are significantly better than the shoes on the market. But at the same time, the resilience performance of sneakers is also more important. Now, we will explore its resilience performance and reflect the strength of its resilience performance through the resilience time. The specific data is shown in Table 5.

From the data in Table 5, it is not difficult to see that the resilience performance of several common brands of basketball shoes on the market is still good. The modulus of resilience of the soles prepared in this experiment differed by 0.1 , which is considered to be an excellent price comparison. The rebound time is also far ahead of other brands of basketball sneakers. The time is only $7.1 \mathrm{~s}$, which is $0.7 \mathrm{~s}$ faster than the second-placed $7.8 \mathrm{~s}$.

\section{The Influence of Sole Printing Parameters on Sole Performance}

4.1. 3D Printing Impact Analysis. This section mainly selects 4 factors of layer height, thickness, printing speed, and nozzle temperature as independent variables. The single factor of KES style and stiffness are tested and orthogonally tested, respectively. This paper analyzes the relationship between $3 \mathrm{D}$ printing parameters and the surface, compression, and tensile properties measured in KES, as well as the influence of printing parameters on the stiffness of the printed sample, and obtains the best combination of process parameters for the corresponding performance. After measuring the bending length and the mass per unit area, the relationship between the printing parameters of the single factor 

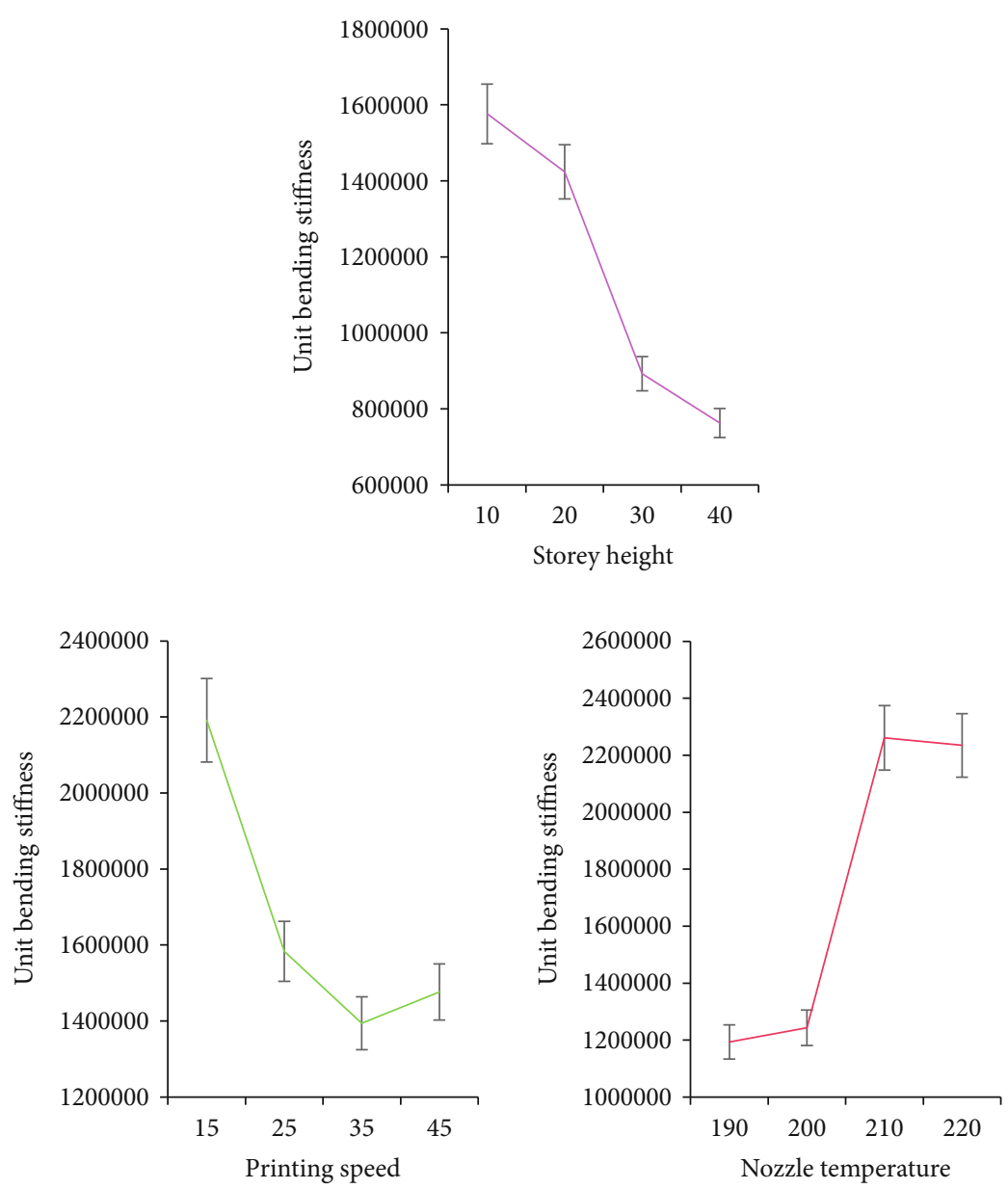

FIgURE 6: The relationship between each single-factor printing parameter and the bending stiffness per unit width.

experiment and the bending stiffness per unit width is shown in Figure 6.

From the Figure 6, we can see that in the range of $0.1 \mathrm{~mm}$ to $0.4 \mathrm{~mm}$, the flexural rigidity per unit width decreases as the layer height increases. That is, the bending deformation ability of the printed sample increases with the increase of the layer height. In the thickness range of $0.5 \mathrm{~mm}$ to $1.0 \mathrm{~mm}$, as the thickness increases, the bending stiffness per unit width increases. That is, the bending deformation ability of the printed sample decreases as the thickness of the printed sample increases. In the printing speed range of $15 \mathrm{~mm} / \mathrm{s}$ to $45 \mathrm{~mm} / \mathrm{s}$, as the printing speed increases, the bending stiffness per unit width decreases first, and the trend tends to be flat around $35 \mathrm{~mm} / \mathrm{s}$. The overall trend is that the bending stiffness per unit width decreases with the increase of printing speed. That is, the bending deformation ability of the printed sample increases as the printing speed increases. In the nozzle temperature range of $190^{\circ} \mathrm{C}$ to $220^{\circ} \mathrm{C}$, as the nozzle temperature increases, the bending stiffness per unit width increases, and the trend gradually becomes gentle. That is, the bending deformation ability of the printed sample decreases with the increase of the temperature of the nozzle. Overall, it has little effect on the antiskid and high resilience performance of sneakers.

\section{Conclusions}

This article mainly studies the preparation of sneaker soles made of high-resilient nonslip composite materials. First, this article analyzes the formula for high resilience. Through formula calculation, by comparing the suitable high resilience interval of the shoe sole, in terms of antislip performance, the pattern of the shoe sole is also analyzed, and the pattern with the best antislip ability is obtained by comparing several patterns. This article mainly studies the preparation of sneaker soles made of high-resilient nonslip composite materials. First, this article analyzes the formula for high resilience. This article uses formula calculations to compare the suitable high resilience interval of the shoe sole. In terms of antislip performance, the pattern of the sole is also analyzed, and the pattern with the best antislip ability is obtained by comparing several patterns.

\section{Data Availability}

The data that support the findings of this study are available from the corresponding author upon reasonable request. 


\section{Conflicts of Interest}

The authors declared no potential conflicts of interest with respect to the research, authorship, and/or publication of this article.

\section{Acknowledgments}

This work was supported by the Foundation of Ph.D. Scientific Research of Neijiang Normal University under grant 18B19, the Sichuan Applied Psychology Research Center of Chengdu Medical College Funded Projects under grant CSXL-21103; and the Innovative Team Program of the Neijiang Normal University under grant 2021TD02.

\section{References}

[1] Y. Liang, J. Sun, S. Huo et al., "Exploration of collector materials in high-power microwave sources," IEEE Transactions on Plasma Science, vol. 46, no. 2, pp. 384-389, 2018.

[2] M. Kakunuri, S. Kaushik, A. Saini, and C. S. Sharma, "SU-8 photoresist-derived electrospun carbon nanofibres as highcapacity anode material for lithium ion battery," Bulletin of Materials Science, vol. 40, no. 3, pp. 435-439, 2017.

[3] H. S. Han, K. H. Lee, and S. H. Park, "Naval-vessel on board equipment base to minimize structure-borne noise," Journal of Mechanical Science \& Technology, vol. 30, no. 12, pp. 5371-5379, 2016.

[4] H. K. Ju, D. H. Mun, G. C. Jeong, and H. G. Park, "Influence of floor dimension and resilient material on heavy impact noise of floating floor system," Transactions of the Korean Society for Noise \& Vibration Engineering, vol. 27, no. 4, pp. 434443, 2017.

[5] J. Xiao, C. F. Wu, Z. H. Zhan, X.-G. Ta, and W.-J. Do, "Research on performances of cement stabilized brick and concrete recycled aggregate base," Zhongguo Gonglu Xuebao/ China Journal of Highway and Transport, vol. 30, no. 2, pp. 25-32, 2017.

[6] J. H. Kim, C. S. Cha, J. Y. Kim, and J. H. Kim, "Development of a process technique for heavy metal removal in the production of recycled synthetic resin materials," Journal of the Korean Society of Manufacturing Process Engineers, vol. 17, no. 4, pp. 137-142, 2018.

[7] Y. Sun, D. Li, J. Wang, D. Gong, and F. Wang, "Preparation of PVC/Fe-rich sludge composites," Hecheng Shuzhi Ji Suliao/ China Synthetic Resin and Plastics, vol. 35, no. 4, pp. 24-27, 2018.

[8] J. Shen, J. Liang, X. Lin, H. Lin, J. Yu, and Z. Yang, "Recent progress in polymer-based building materials," International Journal of Polymer Science, vol. 2020, Article ID 8838160, 15 pages, 2020.

[9] N. Pittala, F. Thétiot, S. Triki, K. Boukheddaden, G. Chastanet, and M. Marchivie, "Cooperative 1D triazole-based spin crossover FeII material with exceptional mechanical resilience," Chemistry of Materials, vol. 29, no. 2, pp. 490-494, 2017.

[10] X. Ge, J. Yang, H. Wang, and W. Shao, "Research on resilience model of emergency material distribution network," Journal of Wuhan University of Technology (Transportation Science and Engineering), vol. 42, no. 5, pp. 727-731, 2018.
[11] B. Sprecher, I. Daigo, W. Spekkink et al., "Novel indicators for the quantification of resilience in critical material supply chains, with a 2010 rare earth crisis case study," Environmental Science \& Technology, vol. 51, no. 7, pp. 3860-3870, 2017.

[12] C. Yang and P. Okumus, "Ultrahigh-performance concrete for posttensioned precast bridge piers for seismic resilience," Journal of Structural Engineering, vol. 143, no. 12, p. 04017161, 2017.

[13] S. S. Shyu, E. Fu, and E. C. Shen, "Clinical and microcomputed topography evaluation of the concentrated growth factors as a sole material in a cystic bony defect in alveolar bone followed by dental implantation: a case report," Implant Dentistry, vol. 25, no. 5, pp. 707-714, 2016.

[14] J. H. Zhao and Y. C. Chang, "Alveolar ridge preservation following tooth extraction using platelet-rich fibrin as the sole grafting material," Journal of Dental Sciences, vol. 11, no. 3, pp. 345-347, 2016.

[15] X. Zhang, Z. Li, X. Wang, and J. Yu, "The fractional KelvinVoigt model for circumferential guided waves in a viscoelastic FGM hollow cylinder," Applied Mathematical Modelling, vol. 89, pp. 299-313, 2021.

[16] Y. Tang, W. Feng, Z. Chen et al., "Fracture behavior of a sustainable material: recycled concrete with waste crumb rubber subjected to elevated temperatures," Journal of Cleaner Production, vol. 318, article 128553, 2021.

[17] S. Aisawa, C. Nakada, H. Hirahara, N. Takahashi, and E. Narita, "Preparation of dipentaerythritol-combined layered double hydroxide particle and its thermostabilizing effect for polyvinyl chloride," Applied Clay Science, vol. 180, no. Nov., p. 105205, 2019.

[18] Y. Wu, H. Qiao, Y. Ding et al., "Properties of pigmented antistatic PVC paste," Hecheng Shuzhi Ji Suliao/China Synthetic Resin and Plastics, vol. 35, no. 3, pp. 17-20, 2018.

[19] Y. Zhang, W. Ni, and Y. Li, "Effect of siliconizing temperature

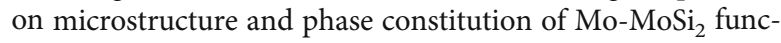
tionally graded materials," Ceramics International, vol. 44, no. 10, pp. 11166-11171, 2018.

[20] Y. Zhang, Y. Li, and C. Bai, "Microstructure and oxidation behavior of $\mathrm{Si}^{-\mathrm{MoSi}_{2}}$ functionally graded coating on Mo substrate," Ceramics International, vol. 43, no. 8, pp. 6250-6256, 2017.

[21] Indian, Leather, Group, "China (Wenzhou) Int'l leather, shoe material \& shoe machinery fair, your first choice!," Indian Leather, vol. 49, no. 12, pp. 217-217, 2016.

[22] K. Lawinska, W. Serweta, I. Jaruga, and N. Popovych, "Examination of selected upper shoe materials based on bamboo fabrics," Fibres \& Textiles in Eastern Europe, vol. 27, no. 6(138), pp. 85-90, 2019.

[23] Z. Czaplicki, Z. Olejniczak, and W. Serweta, "Investigation into the shoe sole materials for the persons over 60 years old," Przeglad Wlokienniczy, vol. 73, no. 5, pp. 29-32, 2019. 